\title{
Evaluating policies to reduce greenhouse gas emissions from private transportation
}

\author{
Yan Liu, Cinzia Cirillo ${ }^{1}$ \\ Department of Civil and Environmental Engineering, University of Maryland, \\ College Park, MD 20742, USA
}

\begin{abstract}
This paper proposes a model system to forecast household greenhouse gas emissions (GHGEs) from private transportation and to evaluate the effects of vehicle-related taxation policies on emission reductions. The proposed model successfully combines an integrated discrete-continuous car ownership model with the Motor Vehicle Emission Simulator 2014 (MOVES2014). Four modeling components are calibrated and applied to the calculation of GHGEs: households' choices of vehicle type and vintage, vehicle quantity, miles traveled, and rates of GHGEs for different vehicle types. The model is applied to the Washington D.C. Metropolitan Area. The 2009 National Household Travel Survey (NHTS). with supplementary data from the Consumer Reports, the American Fact Finder, and the State Motor Vehicle Registrations (SMVR) are used for the estimation. Three tax schemes: vehicle ownership tax, purchase tax and fuel tax are evaluated and their impacts on emission reductions are predicted. We calculate that in the study area the average GHGEs per vehicle is 5.79 tons of carbon dioxide-equivalent $\left(\mathrm{CO}_{2} \mathrm{E}\right)$ gases. Our results show that: (a) a fuel tax is the most effective way to reduce vehicle GHGEs, especially for households with fewer vehicles; (b) a purchase tax reduces vehicle GHGEs mainly by decreasing vehicle quantity for households with more vehicles; and (c) an ownership tax reduces vehicle GHGEs by decreasing both vehicle quantity and miles traveled.
\end{abstract}

Keywords: discrete-continuous car ownership models, vehicle type choice, vehicle miles traveled (VMT), Motor Vehicle Emission Simulator (MOVES), greenhouse gas emissions, taxation policy

\footnotetext{
${ }^{1}$ Corresponding author's address: 3250 Kim Building, College Park, MD 20742, USA. Tel: +1 301405

6864. E-mail addresses: yliu89@umd.edu (Y. Liu), ccirillo@umd.edu (C. Cirillo).
} 


\section{Introduction}

Rising levels of carbon dioxide and other heat-trapping gases in the atmosphere are believed to warm the Earth and to cause wide-ranging impacts. In the long term, scientists project that these trends will continue and in some cases accelerate, posing significant risks to human health and to other natural resources that are vital to the environment. Societies around the globe need to reduce human-caused greenhouse gas emissions (GHGEs) to avoid worsening climate impacts and to reduce the risk of creating changes beyond our ability to respond and adapt. Policies are needed in order to reduce energy use, limit GHGEs, and build a clean energy economy (Department of Ecology, 2015).

According to the annual report of the United Nations Framework Convention on Climate Change (UNFCCC), in the United States (US) more than 27\% of total GHGEs are from the transportation sector. Within this sector, light-duty vehicles are the largest pollutant sources, accounting for $61 \%$ of the total GHGEs (EPA, 2013). The estimation from the Organization for Economic Co-operation and Development (OECD) also shows that on-road passenger cars are responsible for around $15 \%$ of fossil fuel-related carbon dioxide $\left(\mathrm{CO}_{2}\right)$ emissions which are the main component of greenhouse gases (GHGs) (Dargay and Gately, 1997). Although mobile sources contribute large percentages of GHGEs, technology is not yet available to measure and tax emissions from each vehicle (Feng et al., 2005). Therefore, it is necessary to develop and apply effective and quantitative methodologies to support public authority decision making (Liu et al., 2014) and to analyze the impact of taxation policies on reductions of GHGEs.

GHGEs from light-duty vehicles are closely linked to households' car purchasing and driving behaviors. Preferences on vehicle type and quantity (i.e. the number of vehicles within households) determine car purchases, while driving behavior is best described by households' travel demand or vehicle usage (i.e. vehicle miles traveled, VMT). Therefore, the combination of the number of vehicles owned by a household, vehicle type, and the usage (i.e. VMT) of vehicles is an important determinant of households' vehicle GHGEs and fuel consumption (Vyas et al., 2012). The state-of-the-art in calculating GHGEs from vehicle usage employs either the standard values of conversion that consider lifecycle emissions from the Environmental Protection Agency (EPA) or the emission rates per miles from the California Air Resources Board (CARB) (Feng et al., 2005; Fullerton, 2005; Fullerton and Gan, 2005; Musti and Kockelman, 2011). Other methods which estimate vehicle GHGEs combine demand models and emission simulators such as the EPA's MOBILE6, MOVES, or the EMFAC model developed for California.

To estimate GHGEs from private transportation, this paper proposes an integrated model framework that efficiently forecasts the number of vehicle within a household, vehicle type/vintage, annual miles traveled, and the emission rate of each vehicle. Different from previous research, this model framework is able to estimate the usage pattern of households' primary, secondary, and tertiary vehicles. More specifically, it predicts the VMT of each vehicle and forecasts individual vehicle's annual greenhouse gas (GHG) emissions. To the best of our knowledge, this research is the first to forecast households' vehicle emissions by combining an integrated discrete-continuous car ownership model and MOVES2014. Furthermore, the integrated model accounts for different types of attributes such as socio-demographics, built environment, travel costs, 
and road traffic conditions. The proposed study also evaluates several tax schemes by applying the model system to real data extracted from the 2009 U.S. NHTS for the Washington D.C. Metropolitan Area.

The remainder of this paper is organized as follows. Section 2 provides a review of the literature on integrated discrete-continuous car ownership models and on previous methods used to estimate vehicle GHGEs. This is followed by Section 3 where we present the proposed framework based on four modules: vehicle type and vintage choice, quantity choice, usage decision, and GHGEs rates estimator. Section 4 introduces data sources necessary for model estimations, while Section 5 presents model estimation and validation results. In Section 6, three different taxation policies are evaluated and their effects to reduce GHGEs are compared. The final Section offers the concluding remarks and avenues for future research.

\section{Literature Review}

In this section we briefly cover previous studies on vehicle ownership and usage modeling, and we provide main features of existing emission simulators. Additionally, we outline the results obtained from policy analyses on energy and environmental related issues arising from private transportation.

Existing studies in the transportation literature about car ownership modeling attest that vehicle quantity, type/vintage, and usage are the main determinants needed for the calculation of fuel consumption, GHGEs, and other pollutants from private vehicles (Train, 1986). Moreover, researchers have recognized that those decisions are taken simultaneously and that integrated model should be used to model these decisions jointly (Dubin and McFadden, 1984; Hanemann, 1984). The early discrete-continuous models are derived from the conditional indirect utility function and are consistent with the microeconomic theory (Mannering and Winston, 1985; Jong, 1989). More recently, Bhat (Bhat, 2005) has developed multiple discrete-continuous extreme value (MDCEV) models that jointly estimate the holdings and usage of multiple vehicle types by households. Several variables were found to be significant for this problem: socio-demographic variables, built environment attributes, vehicle characteristics, and gasoline prices (Bhat and Sen, 2006; Bhat et al., 2009). However, Bhat's model is restricted by the assumption of fixed total miles traveled by each household. Fang (Fang, 2008) proposed a Bayesian Multivariate Ordered Probit and Tobit (BMOPT) model to estimate households' vehicle type, quantity, and usage. An ordered probit model was employed to determine households' decisions on the number of passenger cars and trucks. A multivariate tobit model was applied to estimate household decisions on VMT. The author concluded that the model was appropriate for predicting changes of vehicle quantity, types, and miles traveled. Liu et al. (2014) also developed an integrated discrete-continuous car ownership model that jointly estimated households' vehicle quantity, type, and usage. A multinomial probit model was employed to estimate vehicle quantity while a linear regression model was used to estimate total VMT of each household. The correlation among the discrete and the continuous parts was captured by an unrestricted full variance-covariance matrix of the unobserved factors.

45 Several emission estimation simulators have been developed and utilized to calculate
46 GHGEs from private vehicles. For instances, the California's Emission Factors model 
(EMFAC7F), the EPA's Vehicle Emission Modeling software (MOBILE5a), and the EPA's MOVES model (EPA, 1998). According to Bai et al. (2009), MOVES should be preferred to other software for the following reasons: (a) it combines vehicle specific power (VSP) and speed bins, rather than speed correction factors, to quantify running exhaust emissions; (b) it uses vehicle operating time rather than VMT as the unit of measure for various vehicle activities and emissions; and (c) it uses a relational database to manipulate data and enables multi-scale emission analyses and applications from linklevel to nation-level.

A significant number of policy-oriented studies have explored market incentives that could be considered to reduce emissions (Eskeland and Devarajan, 1996). Dargay and Gately (1997) applied a car ownership model to forecast the growth of household vehicle quantity to the year 2015 for the Organization for Economic Co-operation and Development (OECD) countries and to estimate the growth of energy demand and emissions. They forecasted fuel consumption and $\mathrm{CO}_{2}$ emissions by estimating trends in car ownership, income, population, vehicle usage, fuel efficiency, and fuel price. Fullerton and Gan (2005) used data from the California Air Resources Board (CARB) on 672 vehicles of various types and ages to estimate miles per gallon (MPG) and emissions per mile (EPM) which were assumed to be a function of vehicle type, age, and number of cylinders. They calculated emissions by using the EPM and other estimates from a discrete-continuous car ownership model. Feng et al. (2005) developed a nested logit structure to model choices among different vehicle bundles, considering the miles traveled and the age of each vehicle as continuous choices. Estimates from the joint model were combined with information on MPG of new vehicles from the EPA's report, EPM from the CARB, and gas prices from the ACCRA cost of living indexes, to calculate vehicle emissions. Musti and Kockelman (2011) utilized a car ownership model to jointly estimate vehicle class and VMT on 596 households extracted from the 2001 NHTS. They translated the estimated VMT into GHGEs by using EPA's conversion factors and fuel economy assumptions (EPA, 2007). Vyas et al. (2012) proposed a joint MDCEV- multinomial logit (MNL) model to estimate households' vehicle quantity, type, annual mileage, and the primary driver for each vehicle. The estimated vehicle type and quantity served as an engine for a household vehicle composition and evolution simulator which is embedded in a larger activity-based travel and emissions forecasting system the Simulator of Activities, Greenhouse Emissions, Energy, Networks, and Travel (SimAGENT) (Goulias et al., 2012).

In addition, various tax schemes have been proposed and investigated to reduce GHGEs, among them we recall: vehicle purchase tax, vehicle ownership tax, tax on vehicle driving distance, emission tax, emission rates tax, fuel tax, tax on vehicle age, and tax on engine size (Fullerton, 2005). Distinct tax weights over different stages of car ownership will have tremendous influences on car purchasing behavior, driving patterns, and $\mathrm{CO}_{2}$ emissions. In this context, Hayashi et al. (2001) proposed a model system that specifically determined effects of different components of taxation policies in the stages of (a) car purchase, (b) car owning, and (c) car usage. The model system was applied to analyze the impact of the 1989 tax reform in Japan and to forecast the future GHGEs reductions under different taxation schemes. Many researchers have found that fuel tax is the most effective strategy for reducing GHGEs among different vehicle-related taxes (Fullerton, 2005; Fullerton and Gan, 2005; Hayashi et al., 2001). For example, Davis and 
1 Kilian (2009) calculated that an additional 10 cent gasoline tax per gallon would reduce 2 vehicle carbon emissions by about $1.5 \%$ in the US. It should be noted that in the long 3 term, the energy consumption and GHGEs of private vehicles would be affected by gas 4 price dynamics, tax incentives, feebates and purchase prices along with new technologies, 5 government-industry partnerships, range and recharging times (Musti and Kockelman, 6 2011; Cirillo et al., 2015).

\section{The Model Framework}

\section{Structure of the Model System}

The proposed framework accounts for households' decisions on vehicle quantity, type/vintage, and usage. Then it estimates GHGEs of each vehicle in a household. An integrated car ownership model, based on discrete choice models and regressions, is combined with MOVES to estimate GHGEs rates of different vehicle types. A flow chart of the modeling structure is given in Fig. 1.

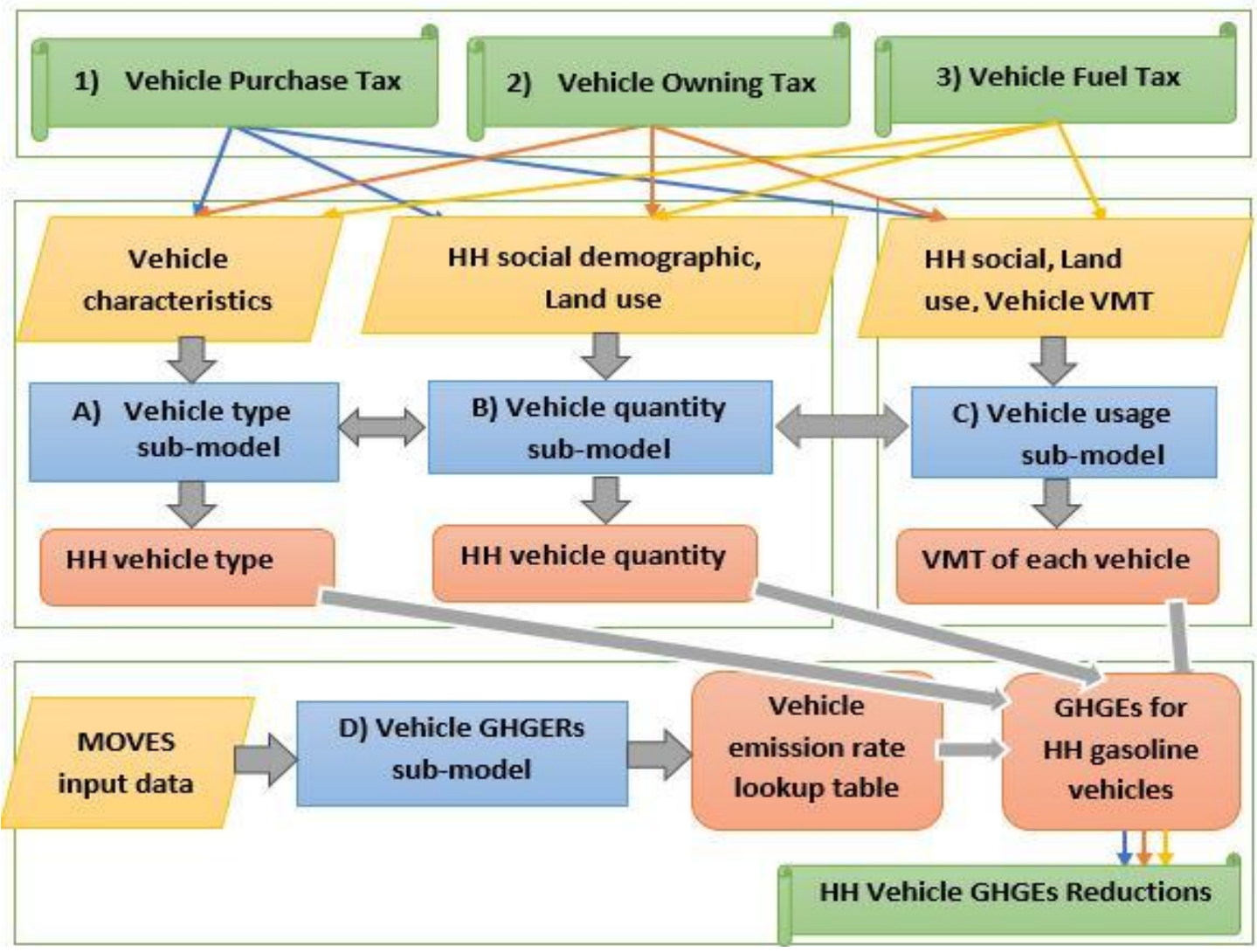

Fig. 1. Structure of the proposed model.

Specifically, the model structure includes four sub-models (in blue): (A) vehicle type logit model, (B) vehicle quantity probit model, (C) car usage (VMT) regression for each vehicle in a household, and (D) vehicle GHGEs rates estimation. The attributes (in yellow) considered are vehicle characteristics, households' social demographics, land use variables, and vehicle traveling information (See Appendix A for a detailed description of 
the independent variables). Effects of three vehicle-related taxes (in green) are evaluated in terms of GHGEs reductions due to their influences on households' discrete choices of vehicle quantity/type and continuous choices of annual VMT.

\section{Vehicle Type and Vintage Sub-model}

We adopt MNL models to capture households' decisions on vehicle type and vintage which are combinations of two types (passenger car and passenger truck) and three vintages (less than 3 years, 3-6 years, and older than 6 years). Let $t_{j}(j=1,2,3)$ represents the choice set of all combinations of vehicle types for households with $\mathrm{j}$ 11 vehicles. $U_{t_{j}}$ represents the indirect utility of choosing any vehicle type $t_{j}^{\prime}$ among the full 12 choice set $t_{j}$.

$$
\begin{gathered}
U_{t_{j}}=V_{t_{j}}+\varepsilon_{t_{j}}, \quad \varepsilon_{t_{j}} \sim_{i i d} \operatorname{EV} 1(0, \lambda) \\
V_{t_{j}}=X_{t_{j}}^{T} \beta_{t_{j}}
\end{gathered}
$$

where $V_{t_{j}}$ and $\varepsilon_{t_{j}}$ are observed and unobserved (error terms) parts of the utility functions. $X_{t_{j}}$ represents the independent variables related to car characteristics, $\beta_{t_{j}}$ are the parameters to be estimated. The error term, $\varepsilon_{t_{j}}$, is independent and identically distributed (IID) and follows type 1 extreme value (EV1) distribution. $\lambda$ is a scale parameter normalized to 1 .

\section{Vehicle Quantity Sub-model}

We employ multinomial probit (MNP) model to forecast households' decisions on vehicle quantity (Liu et al., 2014); the choice set includes four alternatives: owning zero, one, two, and three or more vehicles. The utility function of the vehicle quantity model consists of three parts - the observed utility of vehicle quantity choice $\left(V_{j}\right)$ regardless of vehicle type choice, the information from vehicle type choice $\left(r_{j}\right)$ given $j$ vehicles, and the unobserved error term $\left(\varepsilon_{j}\right)$.

$$
\begin{gathered}
U_{j}=V_{j}+\alpha r_{j}+\varepsilon_{j}, \varepsilon_{j} \sim_{i i d} \mathrm{~N}\left(0, \sigma^{2}\right), j=0,1,2,3 \\
V_{j}=X_{j}^{T} \beta_{j} \\
r_{j}=\mathrm{g}\left(\max \left(U_{t_{j}}\right)\right)
\end{gathered}
$$

where $U_{j}$ is the utility of vehicle quantity choice. $X_{j}$ is the vector of variables contributing to vehicle quantity choice. $\mathrm{g}(*)$ is a statistical function of $\max \left(U_{t_{j}}\right)$, where $U_{t_{j}}$ are the utilities of the vehicle type/vintage model, and $\alpha$ and $\beta_{j}$ are parameters to be estimated.

To specify the information from vehicle type choice given $j$ vehicles, we need to define the distribution of $\max \left(U_{t_{j}}\right)$. 
2 Because vehicle type choice is estimated by MNL model, $v_{j}$ follows type 1 extreme 3 value $(\mathrm{EV} 1)$ distribution with cumulative distribution $\left(F_{v}\right)$ and probability density 4 functions $\left(f_{v}\right)$ as follows (Melnikov, 2013):

$$
\begin{gathered}
F_{v}\left(u ; r_{j}\right)=\exp \left(-e^{-\left(u-r_{j}\right)}\right) \\
f_{v}\left(u ; r_{j}\right)=e^{r_{j}} \exp \left(-e^{-\left(u-r_{j}\right)}-u\right)
\end{gathered}
$$

5

6

where $r_{j}$ is the mode of the following distribution (Melnikov, 2013) for the detail of this formulation):

$$
r_{j}=\ln G\left(\exp \left(V_{t_{j}}\right)\right)
$$

8 where $G\left(V_{t_{j}}\right)=\sum_{t_{j}} V_{t_{j}}$ for MNL model with a Gumbel-distributed error term. Thus, $r_{j}$ can be alternatively represented as follows:

$$
r_{j}=\ln \sum_{t_{j}} \exp \left(V_{t_{j}}\right)=E_{j}\left[\max \left(U_{t_{j}}\right)\right]
$$

where $E_{j}(*)$ is the conditional expectation given $j$ vehicles. The utility of vehicle quantity can be further written as:

$$
\begin{aligned}
& U_{0}=\varepsilon_{0} \\
& U_{1}=V_{1}+\alpha r_{1}+\varepsilon_{1} \\
& U_{2}=V_{2}+\alpha r_{2}+\varepsilon_{2} \\
& U_{3}=V_{3}+\alpha r_{3}+\varepsilon_{3}
\end{aligned}
$$

We assume the error terms follow a multivariate normal distribution with a full, unrestricted covariance matrix. Households are assumed to be rational and make decisions based on utility maximization rule.

For identification purpose, we take the difference of utility. Let $\widetilde{U}_{j y}=U_{j}-U_{y}$, $\tilde{V}_{j y}=\left(\alpha r_{j}+V_{j}\right)-\left(\alpha r_{y}+V_{y}\right), \tilde{\varepsilon}_{j y}=\varepsilon_{j}-\varepsilon_{y}$. The differences of error terms, $\tilde{\varepsilon}_{j y}$, follow normal distributions. Then, the utility in difference is:

$$
\widetilde{U}_{j y}=\tilde{V}_{j y}+\tilde{\varepsilon}_{j y}
$$

where the subscript $y$ represents the chosen alternative and $\mathrm{j}$ represents any alternative within the choice set. Let $Y_{\text {disc }}$ represents households' decisions on vehicle quantity. The likelihood of choosing certain number of vehicles can be calculated as follows:

$$
\mathrm{P}\left(Y_{d i s c}=\mathrm{y}\right)=\int_{R^{3}} I\left(\tilde{V}_{j y}+\tilde{\varepsilon}_{j y}<0, \forall j \neq y\right) \varphi\left(\tilde{\varepsilon}_{j y}\right) d \tilde{\varepsilon}_{j y}
$$


where $I(*)$ is a function indicating that the chosen alternative y has the maximum utility among the choice set. $\varphi(*)$ is the density function of normal distribution. $R^{3}$ indicates the dimension of integrals over $\tilde{\varepsilon}_{j y}$.

\section{Vehicle Usage Sub-model}

We use linear regression models to estimate households' vehicle usage pattern. Three regressions are used for households' primary, secondary, and tertiary vehicles.

$$
\begin{gathered}
Y_{V M T, s}=X_{S}^{T} \beta_{s}+\varepsilon_{s}, \varepsilon_{s} \sim N\left(0, \sigma_{s}^{2}\right) \\
s \in\{\text { primary, scondary, tertiary }\}
\end{gathered}
$$

where $Y_{V M T, s}$ are the dependent variables describing annual miles traveled of each vehicle. $X_{s}$ represents a vector of explanatory variables while $\beta_{s}$ is a vector of corresponding coefficients to be estimated. $\varepsilon_{S}$ is the error term. The regressions are solved with maximum likelihood method (McCulloch et al., 2008). For households with $\mathrm{j}$ vehicles, given:

$$
\begin{gathered}
Y_{V M T}=\left(Y_{V M T, 1 s t}, Y_{V M T}, 2 n d, \ldots \ldots, Y_{V M T, j t h}\right) \\
X=\left(X_{1 s t}, X_{2 n d}, \ldots \ldots, X_{j t h}\right) \\
\beta=\left(\beta_{1 s t}, \beta_{2 n d}, \ldots \ldots, \beta_{j t h}\right) \\
\varepsilon_{V M T}=\left(\varepsilon_{1 s t}, \varepsilon_{2 n d}, \ldots \ldots, \varepsilon_{j t h}\right) \\
\varepsilon_{V M T} \sim \mathrm{N}\left(0, \Sigma_{j}\right) \\
\mathrm{j}=1,2,3
\end{gathered}
$$

where $Y_{V M T, j t h}$ represents the continuous choice on households' VMT of the $\mathrm{j}^{\text {th }}$ vehicle. $X_{j t h}$ is a vector of explanatory variables deciding the VMT of the $\mathrm{j}^{\text {th }}$ vehicle, and $\beta_{j t h}$ is a vector of the corresponding coefficients. $\varepsilon_{V M T}$ is the unobserved error term. $\Sigma_{j}$ is the variance-covariance matrix of size $\mathrm{j} \times \mathrm{j}$. The mileage of different vehicles within one household is jointly estimated by assuming that the error terms of different regressions follow a multivariate normal distribution centered at $X^{T} \beta$. Therefore, the likelihood of observing $Y_{V M T}$ follows a multivariate normal density function:

$$
\mathrm{P}\left(Y_{V M T} \mid X, \beta, \Sigma_{j}\right)=\varphi\left(Y_{V M T} \mid X^{T} \beta, \Sigma_{j}\right)
$$

Instrumental variable (IV) approach, rather than ordinary least squares (OLS), is applied to avoid endogeneity problem due to the inclusion of the driving cost of the household's vehicle as an explanatory variable. Since a household chooses which vehicle it owns, it effectively chooses the driving cost that it faces. Therefore, the driving cost 
that a household faces is an endogenous variable, and estimation with ordinary least squares is biased (Train, 1986). Specifically, we employ the two-stage least squares (2SLS) method to solve the endogeneity problem. In the first stage, the exogenous variables used to predict driving cost are gas price in the residential area, household income, number of workers, living in urban area, age of household head, education level of household head, gender of household head, and residential density. In the second stage, we consider household income, residential density, household head gender, and the estimated driving cost (from the first stage) to forecast annual VMT of households' primary, secondary, and tertiary vehicles.

\section{Integrated Discrete-Continuous Choice Model}

To capture the correlations between households' discrete and continuous choices, we estimate $Y_{\text {disc }}$ and $Y_{V M T}$ jointly. Taking advantage of the fact that both error terms of the regression model and the probit model follow normal distributions, the combination of error terms from the two parts will follow a multivariate normal $(M V N)$ distribution.

$$
\left(\tilde{\varepsilon}_{10}, \tilde{\varepsilon}_{20}, \tilde{\varepsilon}_{30}, \varepsilon_{V M T}\right)=\left(\tilde{\varepsilon}_{10}, \tilde{\varepsilon}_{20}, \tilde{\varepsilon}_{30}, \varepsilon_{1 s t}, \varepsilon_{2 n d}, \ldots \ldots, \varepsilon_{j t h}\right) \sim M V N\left(0, \Sigma_{3+j}\right), j=1,2,3
$$

$\tilde{\varepsilon}_{10}, \tilde{\varepsilon}_{20}, \tilde{\varepsilon}_{30}$ represent error terms in difference of the probit model respective to zerovehicle households. $\varepsilon_{j t h}$ is the error term of households' VMT of the $j^{\text {th }}$ vehicle. We integrate discrete and continuous parts by assuming a full, unrestricted variancecovariance matrix. The dimension of the matrix is $(3+j) \times(3+j)$. The number of vehicles $\mathrm{j}$ vary across different households.

Liu's simulation results (Liu, 2013) show that the joint probability $P\left(Y_{\text {disc }}, Y_{V M T}\right)$ is more appropriate to be expressed as the product of the marginal probability of driving certain miles $P\left(Y_{V M T}\right)$ and the conditional probability of choosing the number of vehicles based on VMT $P\left(Y_{\text {disc }} \mid Y_{V M T}\right)$.

$$
P\left(Y_{\text {disc }}, Y_{V M T}\right)=P\left(Y_{V M T}\right) P\left(Y_{\text {disc }} \mid Y_{V M T}\right)
$$

The second part follows a MVN distribution with new mean and variancecovariance matrix.

$$
\begin{gathered}
\text { If }\left[\begin{array}{l}
\varepsilon_{\text {disc }} \\
\varepsilon_{V M T}
\end{array}\right] \sim N\left(\left[\begin{array}{l}
0 \\
0
\end{array}\right],\left[\begin{array}{cc}
\Sigma_{\text {disc }} & \Sigma_{\text {disc,VMT }} \\
\Sigma_{V M T, \text { disc }} & \Sigma_{V M T}
\end{array}\right]\right) \\
\text { Then } \varepsilon_{\text {disc,VMT }} \sim N\left(0+\frac{\Sigma_{\text {disc,VMT }}}{\Sigma_{V M T}}(\text { err }-0), \quad \Sigma_{\text {disc }}-\frac{\Sigma_{\text {disc }, V M T} \Sigma_{V M T, \text { disc }}}{\Sigma_{V M T}}\right)
\end{gathered}
$$

where $\varepsilon_{d i s c, V M T}$ is the integrated error term, and $\operatorname{err}$ represents observed errors.

\section{Vehicle GHGEs Rates Sub-model}

We employ MOVES2014 to estimate vehicle emission rates for the main components of GHGs - $\mathrm{CO}_{2}$, methane $\left(\mathrm{CH}_{4}\right)$, and nitrous oxide $\left(\mathrm{N}_{2} \mathrm{O}\right)$ emitted from vehicle tailpipe. The amounts of $\mathrm{CH}_{4}$ and $\mathrm{N}_{2} \mathrm{O}$ emissions are less than $\mathrm{CO}_{2}$, however, these gases have 
higher potential global warming effects (EPA, 2011). Thus, emission rates of all gases are transformed into carbon dioxide equivalent $\left(\mathrm{CO}_{2} \mathrm{E}\right)$ gases for comparison purpose. Vehicle emission rates not only depend on vehicle characteristics (i.e. vehicle size and model year), but also depend on driving information (i.e. start time and speed), traffic condition (i.e. total number of vehicles and mileage), and environment factors (i.e. meteorology). We consider two vehicle types (passenger car and passenger truck) and three vintages (less than 3 years, 3-6 years, older than 6 years) which are consistent with the vehicle classification in the vehicle type sub-model. Vehicle GHGEs are from two driving processes - running process and start/extended idle process. The specific emission rates estimation flowchart is illustrated in Fig. 2.

The inputs of MOVES consist a run specification (Run Spec) and input data files. The run specification contains scenario description, scale, inventory or emission rates, time spans, geographic bounds, vehicles or equipment, road type, pollutants and processes, and output. Input data files, which correspond to the run specification, contain: (a) source type population; (b) vehicle type VMT; (c) maintenance programs; (d) fuel type and technology; (e) fuel and formulation; (f) meteorology; (g) ramp fraction; (h) road type distribution; (i) age distribution; and (j) average speed distribution.

In this research, we estimate vehicle emission rates for the Washington D.C. Metropolitan Area which spans four states - District of Columbia, Maryland, Virginia and West Virginia, encompassing eighteen counties. Thus, we choose the scale of countylevel in the run specification. To avoid predicting emission rates for all eighteen counties, a cluster analysis is adopted to classify the counties into five groups based on the total number of vehicles and total mileage traveled in each county. Average vehicle emission rates for the Washington D.C. Metropolitan Area are calculated as a weighted average over five county groups. Besides, to forecast GHGEs for each household vehicle in the target area, we choose emission rates instead of inventory. 


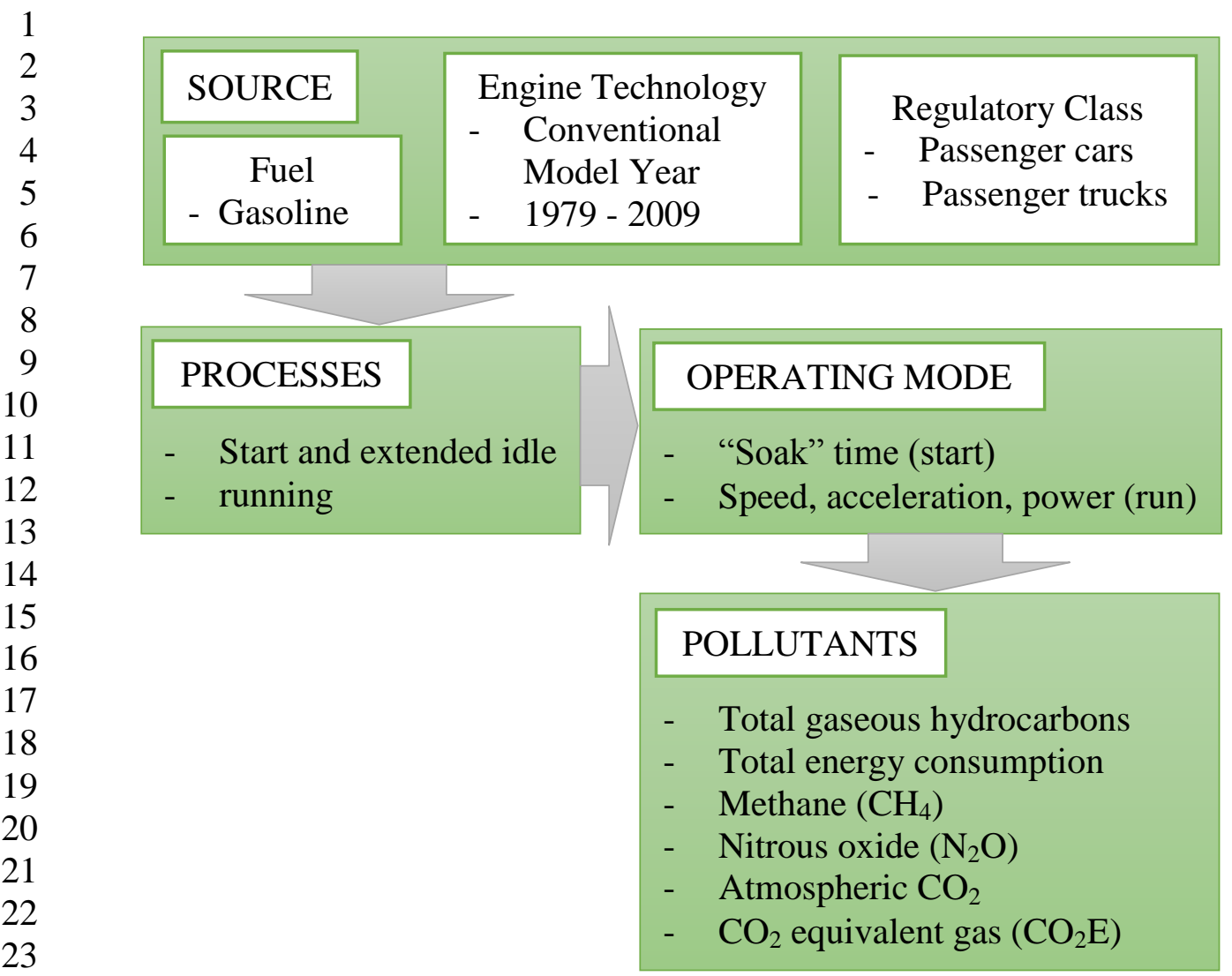

Fig. 2. Emission rates estimation flowchart (based on MOVES documentation).

\section{Household Vehicle GHGEs Calculation}

In our modeling framework, we obtain the information on households' vehicle type and vintage, quantity, annual miles traveled, running emission rates, and start/extended idle emission rates for different vehicle types. We then calculate annual GHGEs for each household vehicle according to the following formula:

$$
\operatorname{AGHGES}\left(\frac{\text { grams }}{\text { vehicle-year }}\right)=\operatorname{RERS}\left(\frac{\text { grams }}{\text { vehicle-mile }}\right) \times \operatorname{AVMT}\left(\frac{\text { miles }}{\text { year }}\right)+\operatorname{SERs}\left(\frac{\text { grams }}{\text { vehicle-day }}\right) \times D_{s}\left(\frac{\text { days }}{\text { year }}\right)
$$

Where AGHGEs is annual GHGEs. RERs and SERs represent running emission rates and start/extended idle emission rates, respectively. $A V M T$ represents annual VMT. $D_{S}$ is the effective number of weekdays per year when vehicle s is utilized. $D_{S}$ is calculated as follows:

$$
D_{s}\left(\frac{\text { days }}{\text { year }}\right)=W_{d}\left(\frac{\text { days }}{\text { year }}\right) \times \alpha_{s}+W_{e}\left(\frac{\text { days }}{\text { year }}\right) \times \beta_{s} \times \gamma
$$

Where $W_{d}$ equals 261, which is the number of weekdays in 2009; $W_{e}$ equals 104 , which is the number of weekends in 2009; $\alpha_{s}$ represents the utilization rate of vehicle $\mathrm{s}$ during weekdays, while $\beta_{s}$ represents the utilization rate of vehicle s during weekends. $\gamma$ 
1 is a factor to scale from weekend emissions to weekday emissions, $s$ represents 2 households' primary, secondary, and tertiary vehicles. the scale factor from daily vehicle 3 start emissions to annual vehicle start emissions. Although the number of driving days 4 per year is not available for each households' vehicle, the NHTS sample in the 5 Washington D.C. Metropolitan area provides 20,409 observations of individuals' daily 6 activities from 2,218 households from April 2008 to April 2009. From this sample, the 7 three factors in eq. $20(\alpha, \beta$, and $\gamma)$ were calculated.

\section{Data Sources}

The primary data source used for this research is the 2009 NHTS. After data processing and cleaning, 1289 household records are available for the study area. The data file mainly contains information for households' characteristics (i.e. income level, number of adults, number of workers, number of drivers, age, gender, education level, and etc.), car ownership (i.e. number of household cars, vehicle make, model, model year, and etc.), and land use (i.e. housing units per square mile, population per square mile, and etc.). Fig. 3 (1-5) shows descriptive statistics related to our sample in the Washington D.C. Metropolitan Area. The shares of households with zero, one, two, and three or more vehicles are $8.3 \%, 25.6 \%, 46.2 \%$, and $19.9 \%$ respectively. The percentage of zerovehicle households is $8.3 \%$, higher than the national average $4.8 \%$, due to high population density of the study area. The average number of vehicles per household is 1.77, slightly lower than the national average 1.91. Fig. 3 (2) illustrates the distribution of six different vehicle types which is consistent with vehicle type sub-model and MOVES. The figure shows that households with more vehicles tend to have higher percentage of passenger trucks than cars. Households with one vehicle prefer passenger cars $(70 \%)$ to trucks (30\%), while households with two or more vehicles have no obvious preference on passenger car or truck. Additionally, around half of the vehicles in the sample are older than six years.

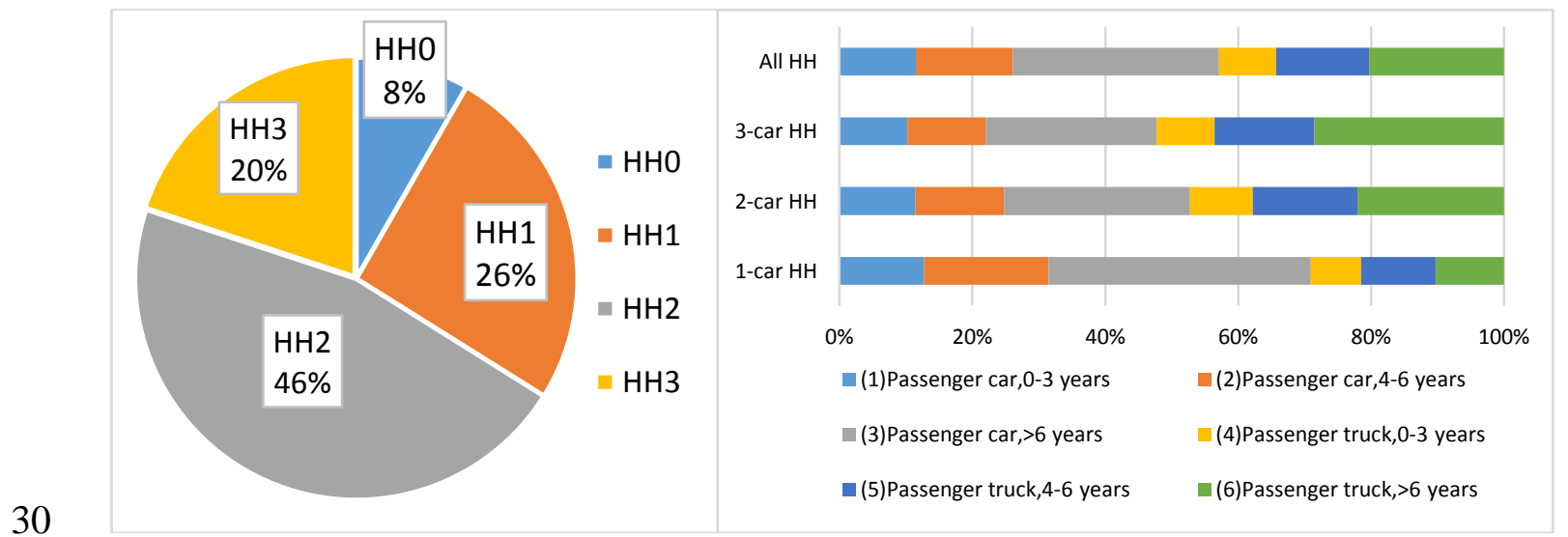




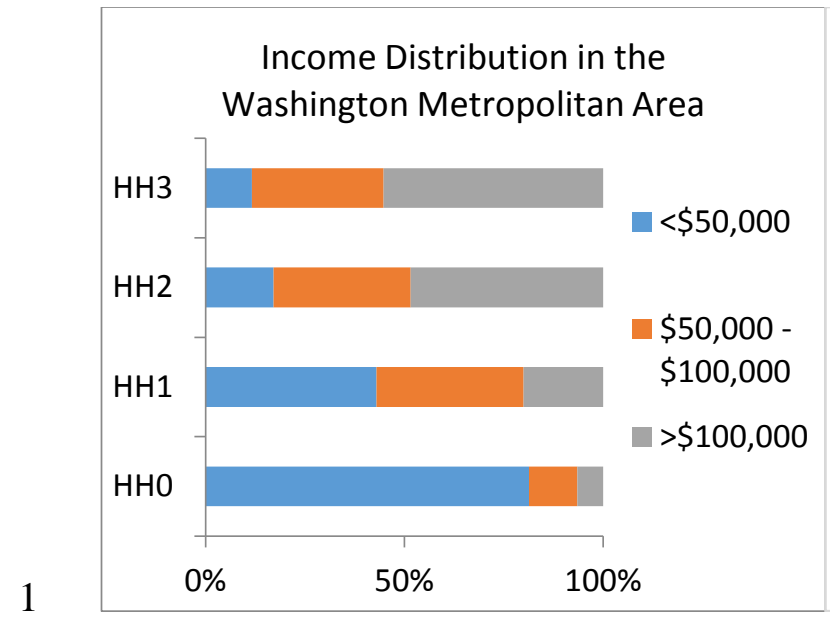

(3)

2

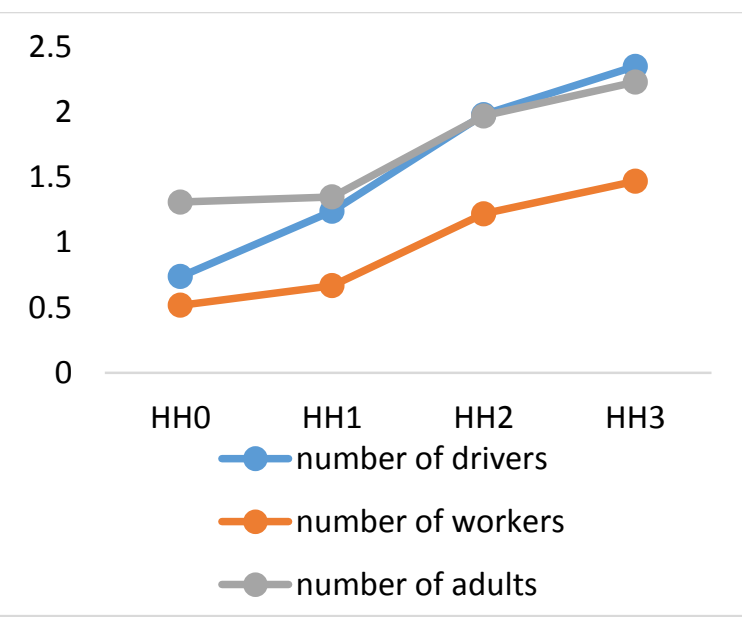

(4)

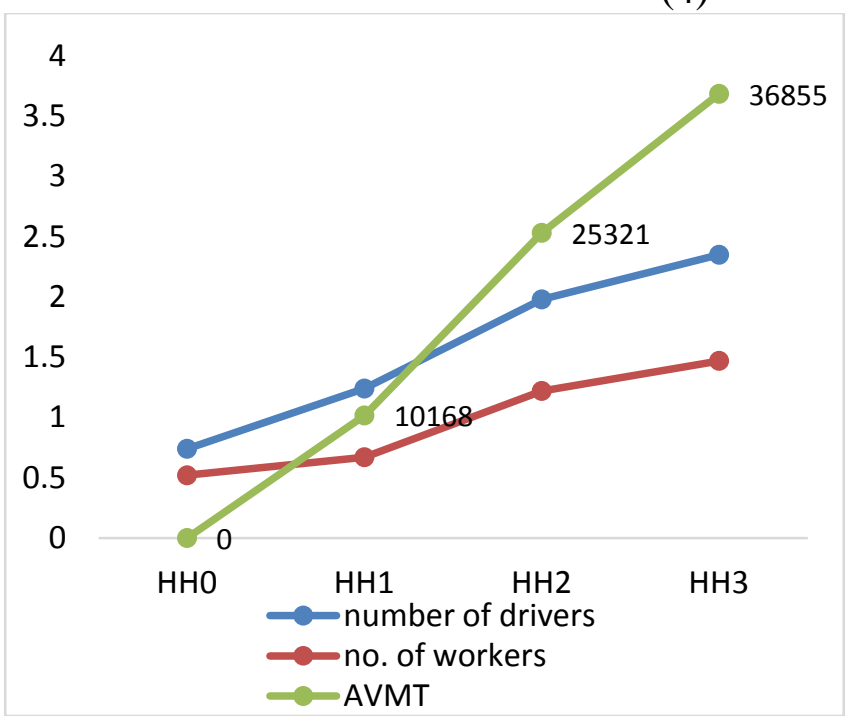

(5) Households' socio-demographic and land use variables have great influence on car
ownership and usage decisions. In the Washington D.C. Metropolitan Area, households' income and education level are higher than the national average. Households with more vehicles tend to have higher income level, as showed in Fig. 3 (3), and they tend to live in less dense or rural areas. In Fig. 3 (3-5), axes labeled "HH0", "HH1", "HH2", and "HH3" represent households with zero, one, two, and three vehicles respectively. Fig. 3 (4) describes the relationship between households' size and the number of workers, drivers, and adults. The vertical axes in Fig. 3 (4-5) represent the number of individuals. The number of workers, drivers, and annual VMT increase with households' size, as described in Fig. 3 (5).

The four supplementary data sources used in this study are the Consumer Reports, the American Fact Finder, the 2009 SMVR, and MOVES default database. Data from Consumer Reports provides vehicle characteristics including vehicle price, seating space, engine size, transmission, acceleration, shoulder room, etc., which are associated to vehicle type decisions. The American Fact Finder provides residential population, while 
1 the 2009 SMVR data gives vehicle population in the study area which is essential for

2 emission rates estimation. Information on road condition and weather such as ramp and 3 meteorology (temperature and humility) are derived from MOVES default database.

4

Model Estimation and Validation Results

\section{Results for Integrated Discrete-Continuous Car Ownership Sub-Model}

The framework of the integrated car ownership sub-model jointly estimates vehicle type, quantity, and annual miles traveled for households' primary, secondary, and tertiary vehicles. Primary vehicle is defined as the one used the most by a household while tertiary vehicle is the one used the least. We first calculate the mode of utilities from vehicle type logit model, which serves as a variable in the utility function of vehicle quantity choice. We estimate the integrated model on the sample of 1289 observations for the Washington D.C. Metropolitan Area. The number of observations for households' primary, secondary, and tertiary vehicles from the sample are 1182, 852, and 257 respectively. Table 1 reports estimation results of the integrated discrete-continuous model.

21 Integrated discrete-continuous model: estimation results.

\begin{tabular}{|c|c|c|c|c|}
\hline Variable & Alternative & Coefficient & $\begin{array}{c}\text { Standard } \\
\text { Deviation }\end{array}$ & p-value \\
\hline Mode of type / vintage & all & 0.801 & 0.123 & $<0.001$ \\
\hline \multirow{4}{*}{ Constant } & 1 car & -6.492 & 0.886 & $<0.001$ \\
\cline { 2 - 5 } & 2 cars & -19.880 & 1.269 & $<0.001$ \\
\cline { 2 - 5 } & 3 cars & -24.995 & 1.114 & $<0.001$ \\
\hline \multirow{4}{*}{ Low income } & 1 car & 0.104 & 0.029 & $<0.001$ \\
\cline { 2 - 5 } & 2 cars & 0.227 & 0.040 & $<0.001$ \\
\cline { 2 - 5 } & 3 cars & 0.399 & 0.036 & $<0.001$ \\
\hline \multirow{4}{*}{ Middle income } & 1 car & 0.123 & 0.025 & $<0.001$ \\
\cline { 2 - 5 } & 2 cars & 0.266 & 0.052 & $<0.001$ \\
\cline { 2 - 5 } & 3 cars & 0.160 & 0.043 & $<0.001$ \\
\hline \multirow{3}{*}{ High income } & 1 car & 0.002 & 0.105 & 0.983 \\
\cline { 2 - 5 } & 2 cars & 0.147 & 0.026 & $<0.001$ \\
\cline { 2 - 5 } & 3 cars & 0.100 & 0.026 & $<0.001$ \\
\hline \multirow{2}{*}{ Number of drivers } & 1 car & 1.101 & 0.624 & 0.078 \\
\cline { 2 - 5 } & 2 cars & 2.961 & 0.837 & $<0.001$ \\
\cline { 2 - 5 } & 3 cars & 3.974 & 1.137 & $<0.001$ \\
\hline Household head gender & 1 car & 0.740 & 0.201 & $<0.001$ \\
\cline { 2 - 5 } (1 for Male) & 2 cars & 1.262 & 0.638 & 0.048 \\
\cline { 2 - 5 } & 3 cars & 1.360 & 0.358 & $<0.001$ \\
\hline Residential Density / low & 1 car & -0.154 & 0.024 & $<0.001$ \\
\cline { 2 - 5 } income & 2 cars & -0.349 & 0.078 & $<0.001$ \\
\hline
\end{tabular}




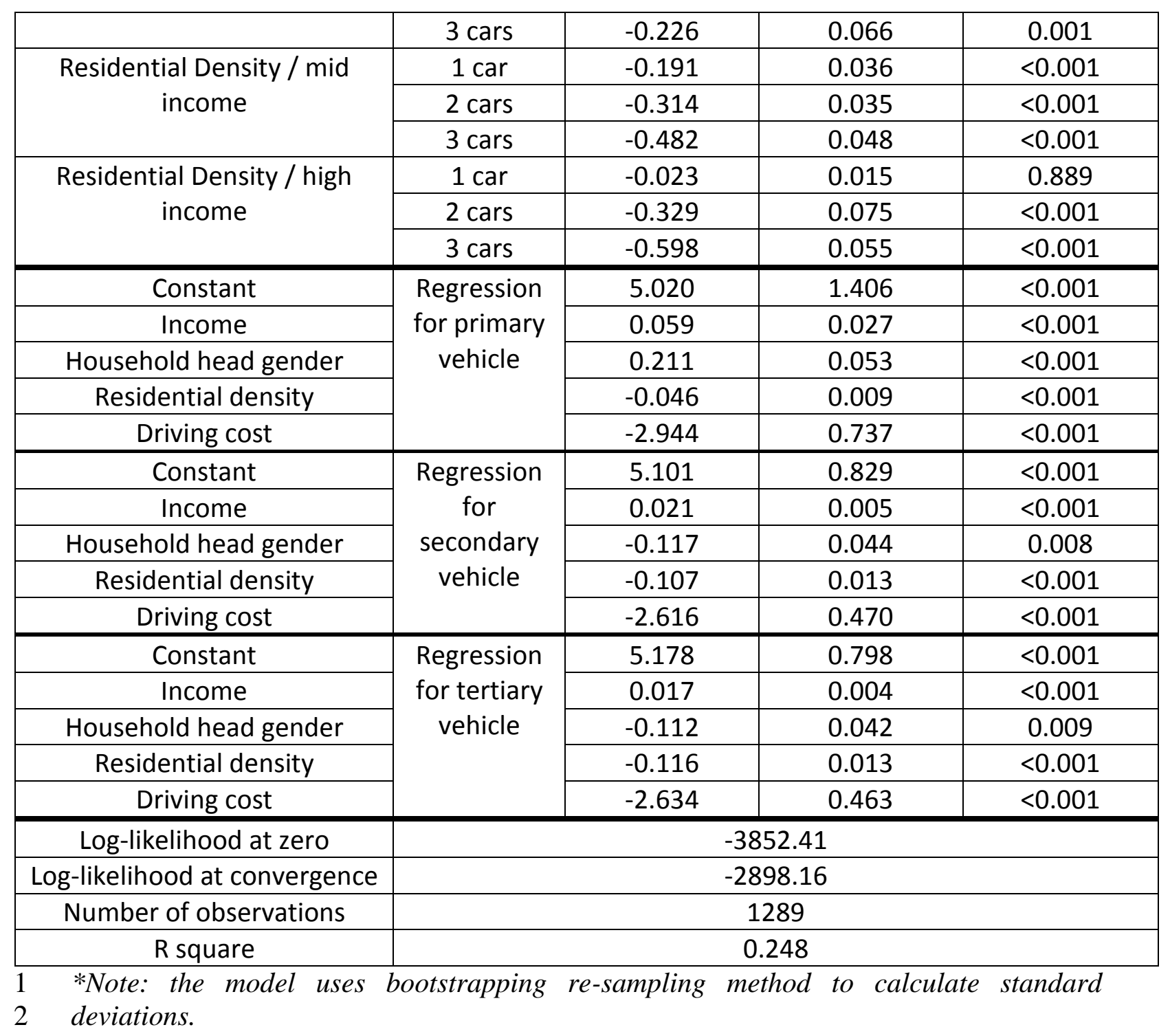

3 The estimation results of the integrated model can be interpreted as follows. The 4 "Mode of type/vintage" represents the expected maximum utility of choosing vehicle 5 type and vintage. The corresponding parameter is significant and between zero and one.

6 The coefficients of households' income are positive which indicate that households 7 with higher income tend to have more vehicles and drive more. For low-income group, 8 the value of income coefficient is larger, indicating that income has higher impact for 9 households with more vehicles. In addition, for three-car households, the value of income 10 coefficient is larger for households with lower income, which indicates income has a 11 higher impact on the low-income group.

12 The positive coefficients of the number of drivers indicate that households prefer to 13 have more vehicles if there are more drivers within the households. This variable has 14 higher impact on households with more vehicles.

15 The positive coefficients of household head gender indicate male household heads 16 are more likely to have more vehicles and to drive the primary vehicle more frequently. 17 The negative coefficients of household head gender in the regressions for secondary and 
tertiary vehicles show that females are more likely to drive the secondary and tertiary vehicles.

The negative coefficients of residential density indicate that households living in areas with higher population density prefer to have fewer vehicles and to drive less. Households living in suburban or rural areas are more likely to have more vehicles. In addition, for middle-income and high-income groups, the absolute value of residential density coefficient is higher, indicating higher impact for households with more vehicles.

The negative coefficients of driving cost indicate that households tend to drive less under higher fuel cost as expected. The values of the coefficients illustrate that the usage of primary car is more sensitive to fuel cost.

\section{Car Ownership Sub-Model Validation}

For validation purpose, the entire sample size has been divided into two parts; the estimation sample contains $80 \%$ of the population while the application sample contains the remaining $20 \%$ of the observations. We report the actual vehicle ownership and usage, the predicted vehicle ownership and usage, and their differences in Table 2. The results show that overall the model is able to reproduce actual choices but it slightly underestimates vehicle ownership and the average annual vehicle miles traveled (AAVMT).

\section{Table 2}

Joint discrete-continuous model: validation results.

\begin{tabular}{|c|c|c|c|c|}
\hline \multirow{3}{*}{ Car Ownership } & & Actual & Forecast & Difference \\
\cline { 2 - 5 } & 0-car household & $10.9 \%$ & $13.2 \%$ & $2.3 \%$ \\
\cline { 2 - 5 } & 1-car household & $22.6 \%$ & $22.6 \%$ & $0.0 \%$ \\
\cline { 2 - 5 } & 2-car household & $45.5 \%$ & $44.7 \%$ & $-0.8 \%$ \\
\cline { 2 - 5 } & 3-car household & $21.1 \%$ & $19.5 \%$ & $-1.5 \%$ \\
\cline { 2 - 5 } & Average car ownership & 1.77 & 1.71 & $-3.4 \%$ \\
\hline \multirow{7}{*}{ AAVMT } & Primary car mileage & 11753.3 & 11960.7 & $1.8 \%$ \\
\cline { 2 - 5 } & Secondary car mileage & 12790.7 & 12310.5 & $-3.8 \%$ \\
\cline { 2 - 5 } & Tertiary car mileage & 12095.2 & 10372.6 & $-14.2 \%$ \\
\cline { 2 - 5 } & Average mileage & 12159.7 & 11906.6 & $-2.1 \%$ \\
\hline
\end{tabular}

\section{Results for Vehicle GHGEs Rates Sub-Model}

We employ MOVES2014 to estimate the average emission rates of the main components of greenhouse gases for the Washington D.C. Metropolitan Area. A cluster analysis is utilized to categorize eighteen counties in the target area into five groups based on factors such as vehicle population and total VMT in each county. The average GHGEs rates are calculated as the weighted average of emission rates over the five groups. Several assumptions are made for estimation: (a) the average annual GHGEs rates are the average emission rates of typical summer months (July and August) and 34 typical winter months (January and February); (b) only gasoline vehicles are considered; 
(c) we only consider emission rates for weekdays; (d) we assume the number of vehicles

Table 3

Washington D.C. Metropolitan Area: running emission rates.

\begin{tabular}{|c|c|c|c|c|c|c|c|c|}
\hline Weighted & \multicolumn{4}{|c|}{ Passenger Car } & \multicolumn{4}{c|}{ Passenger Truck } \\
\hline age & $\mathrm{CH}_{4}$ & $\mathrm{~N}_{2} \mathrm{O}$ & $\mathrm{CO}_{2}$ & $\mathrm{CO}_{2} \mathrm{E}$ & $\mathrm{CH}_{4}$ & $\mathrm{~N}_{2} \mathrm{O}$ & $\mathrm{CO}_{2}$ & $\mathrm{CO}_{2} \mathrm{E}$ \\
\hline 0-3 year & 0.004 & 0.008 & 399.109 & 401.647 & 0.004 & 0.020 & 577.547 & 583.674 \\
\hline 4-6 year & 0.004 & 0.008 & 399.224 & 401.770 & 0.009 & 0.021 & 577.763 & 584.304 \\
\hline$>6$ year & 0.004 & 0.008 & 399.340 & 401.893 & 0.008 & 0.020 & 579.010 & 585.320 \\
\hline
\end{tabular}

\section{Table 4}

Washington D.C. Metropolitan Area: start and extended idle emission rates.

\begin{tabular}{|c|c|c|c|c|c|c|c|c|}
\hline Weighted & \multicolumn{4}{|c|}{ Passenger Car } & \multicolumn{4}{c|}{ Passenger Truck } \\
\hline age & $\mathrm{CH}_{4}$ & $\mathrm{~N}_{2} \mathrm{O}$ & $\mathrm{CO}_{2}$ & $\mathrm{CO}_{2} \mathrm{E}$ & $\mathrm{CH}_{4}$ & $\mathrm{~N}_{2} \mathrm{O}$ & $\mathrm{CO}_{2}$ & $\mathrm{CO}_{2} \mathrm{E}$ \\
\hline 0-3 year & 0.280 & 0.856 & 605.113 & 677.185 & 0.397 & 1.160 & 786.046 & 884.202 \\
\hline 4-6 year & 0.333 & 0.856 & 605.115 & 678.293 & 0.527 & 1.176 & 784.166 & 886.487 \\
\hline >6 year & 0.141 & 0.856 & 605.113 & 674.267 & 0.308 & 1.152 & 784.068 & 879.697 \\
\hline
\end{tabular}

The results show that in the Washington D.C. Metropolitan Area, the average running $\mathrm{CO}_{2} \mathrm{E}$ emission rates for passenger car and truck are 402 grams/mile and 584 grams/mile respectively; and the average start/extended idle $\mathrm{CO}_{2} \mathrm{E}$ emission rates for passenger car and truck is about 677 grams/day and 884 grams/day. The start/extended idle emission rates are higher for counties with higher vehicle population, while there is no significant variation for running emission rates over different counties. Moreover, the start/extended idle emission rates in winter are much higher than those in summer, which is reasonable due to longer start time and more fuel consumptions at low temperature (Mcmichael and Sigsby, 1966; Vijayaraghavan, 2012).

\section{Results for Household Vehicle GHGEs}

The estimations of households' vehicle type and vintage, vehicle quantity, annual VMT for each vehicle, and GHGEs rates for different vehicle types are then used to calculate households' average annual vehicle GHGEs (See equation 19). 


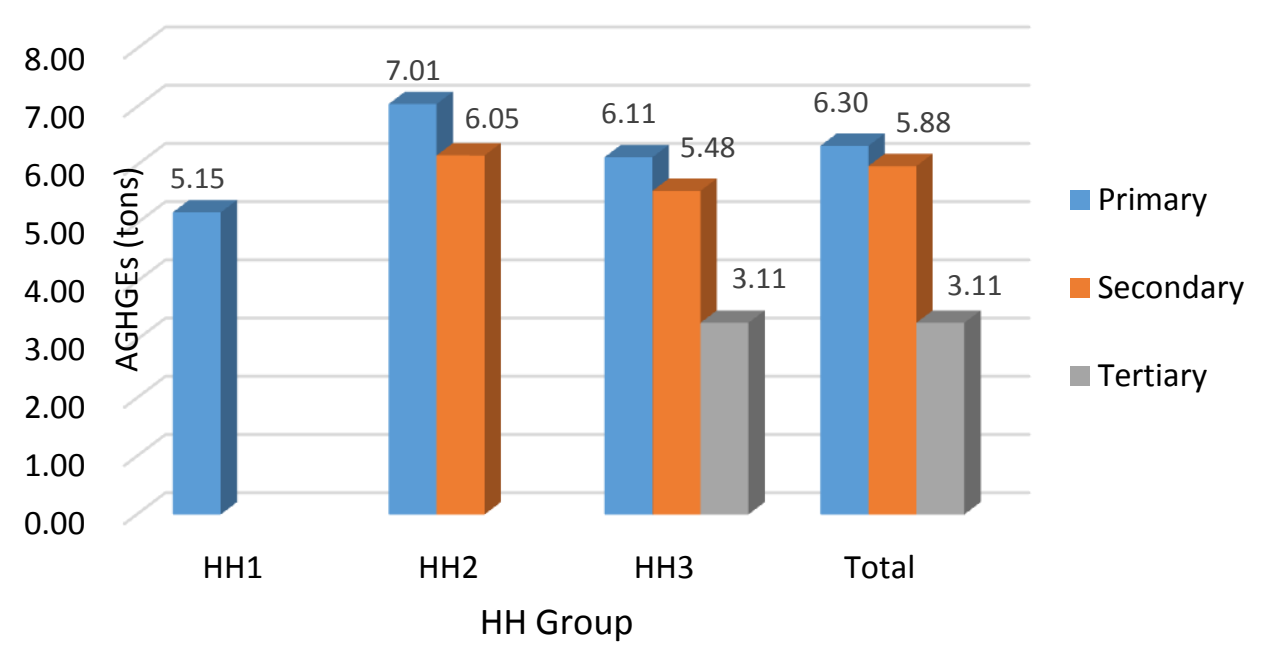

Fig. 4. Annual GHGEs for households' primary, secondary, and tertiary vehicles.

Fig. 4 shows the average annual GHGEs for households' primary, secondary, and tertiary vehicles. We can observe that the primary vehicles produce the highest emissions because they are used most frequently. On the contrary, the tertiary vehicles produce the lowest emissions because they are not frequently in use. For households with one vehicle, the average annual GHG emission is 5.15 tons which is consistent with the 2013 annual report from the EPA. On average, the annual GHGEs for households' primary, secondary, and tertiary vehicles are 6.30 tons, 5.88 tons and 3.11 tons respectively.

\section{Policy Analysis}

In the US, three main vehicle-related taxes are applied during different stages of a vehicle lifetime: purchase tax, ownership tax and fuel tax (Hayashi et al., 2001). In this section, we propose three policy plans to test and compare impacts of reducing vehicle GHGEs from the three vehicle-related taxes. For comparison purpose, equivalent increments of $\$ 92.5, \$ 185$, and $\$ 370$ additional annual fee are considered for the three plans respectively (Liu and Cirillo, 2015). Table 5 shows the specification of the three policy plans based on data provided by the 2009 NHTS.

\section{Table 5}

Taxation policy plan.

\begin{tabular}{|c|c|c|c|c|}
\hline Equivalent increment & Plan ID & Purchase tax & Ownership tax & Fuel tax \\
\hline$\$ 92.5 /$ car \& year & 1 & $+10 \%$ & Income-\$92.5/car & $+5 \%$ \\
\hline$\$ 185 /$ car \& year & 2 & $+20 \%$ & Income-\$185/car & $+10 \%$ \\
\hline \$370/ car \& year & 3 & $+40 \%$ & Income-\$370/car & $+20 \%$ \\
\hline
\end{tabular}

\section{Sensitivity Analysis for Purchase Tax}

Purchase tax is a tax on vehicle purchase price. In the three policy plans, the proposed purchase tax is equivalent to an additional charge of $10 \%, 20 \%$, and $40 \%$ of the current vehicle price. Purchase tax is expected to reduce the number of vehicles within 
1 households. Fig. 5 shows annual GHGEs reduction rates under the three purchase tax 2 plans.

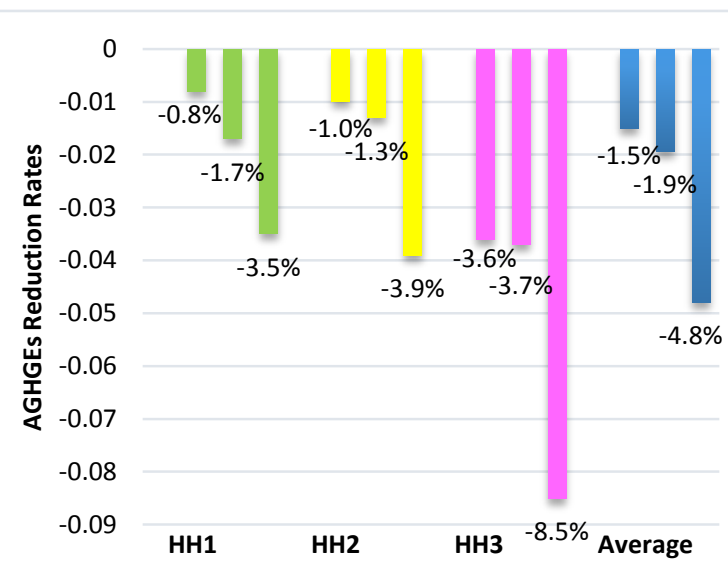

(A)

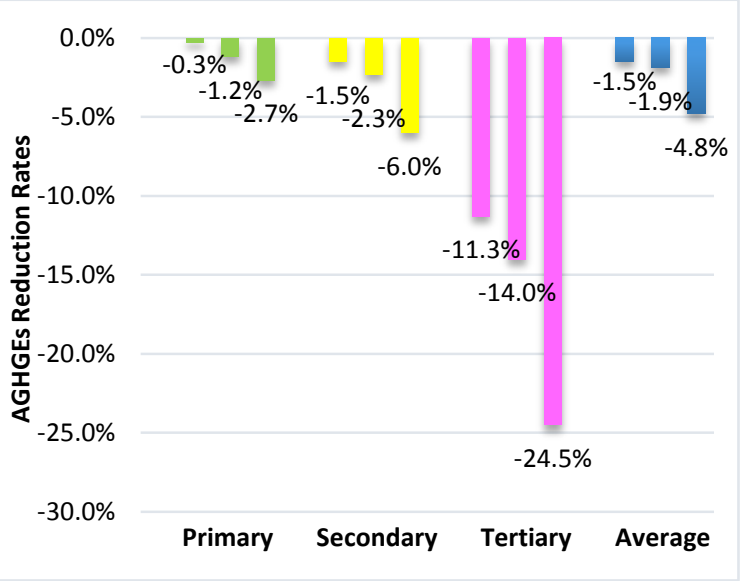

(B)

Fig. 5. Annual GHGEs reduction rates under purchase tax.

Fig. 5 (A) presents the annual GHGEs reduction rates for households with one, two, and three vehicles under the three policy plans. We can observe that the purchase tax reduces annual vehicle GHGEs under all three plans and it is more effective in reducing emissions from households with more vehicles. Fig. 5 (B) illustrates GHGEs reduction rates for households' primary, secondary, and tertiary vehicles. Correspondingly, we can observe purchase tax mainly reduce emissions for tertiary vehicles. For households with 14 one and two vehicles, the reduction rates are small which indicates that these groups hold 15 the number of vehicles that satisfies their basic travel demands. On average, the 16 implementation of the three policy plans reduces households' annual GHGEs by $1.5 \%$, $17 \quad 1.9 \%$, and $4.8 \%$.

\section{Sensitivity Analysis for Ownership Tax}

Ownership tax is an annual fee for each vehicle. In the three policy plans, we propose an additional annual charge of $\$ 92.5, \$ 185$, and $\$ 370$ per vehicle, subtracting from households' income. Fig. 6 shows annual GHGEs reduction rates under the three ownership tax plans. 


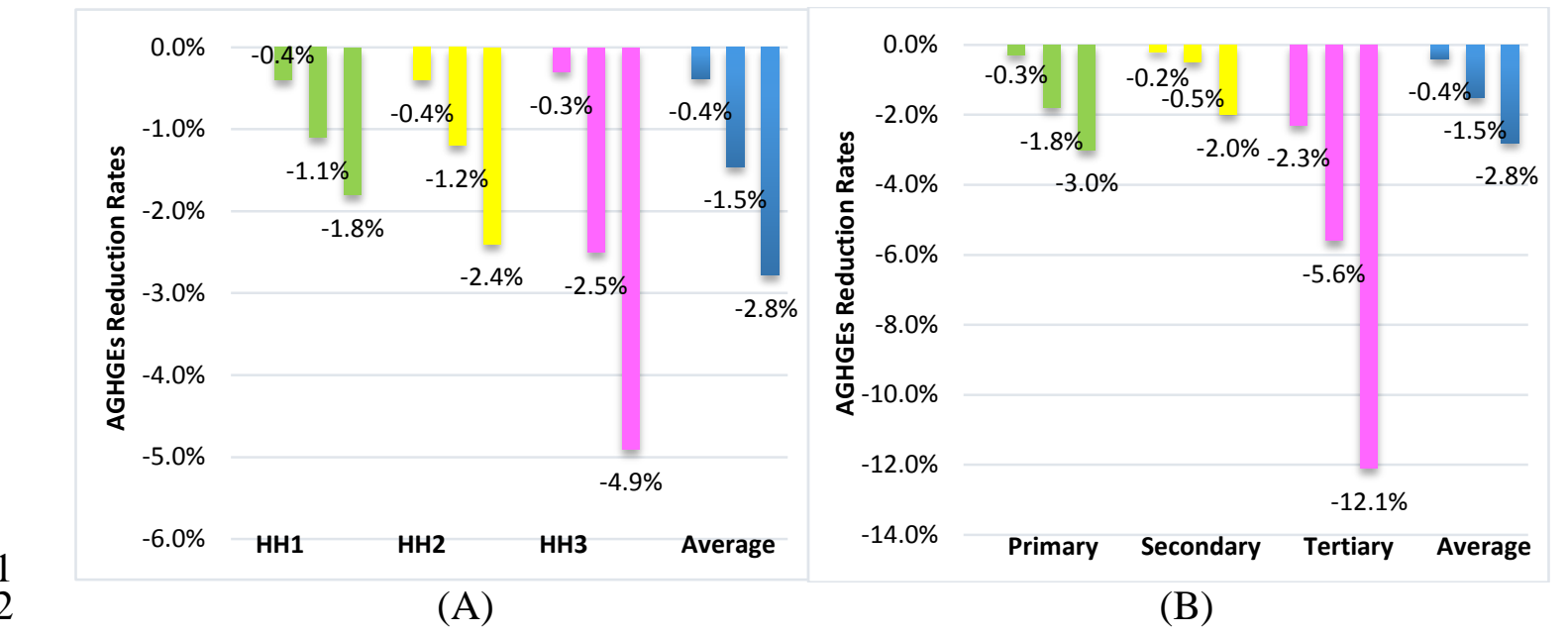

Fig. 6. Annual GHGEs reduction rates under ownership tax.

As expected, ownership tax is able to reduce vehicle GHGEs under all three policy plans. Although ownership tax is not as effective to reduce emissions as purchase tax, it also has higher impact for households with more vehicles. In addition, ownership tax mainly reduces emissions for households' tertiary vehicles. On average, the implementation of the three policy plans reduces households' annual GHGEs by $0.4 \%$, $10 \quad 1.5 \%$, and $2.8 \%$.

\section{Sensitivity Analysis for Fuel Tax}

Fuel tax is a tax on gas consumption. In the three policy plans, the proposed fuel tax is equivalent to an additional charge of $5 \%, 10 \%$, and $20 \%$ of the gas price. Fuel tax is expected to decrease households' vehicle usage for the study area. Fig. 7 shows annual 18 GHGEs reduction rates under the three fuel tax plans.

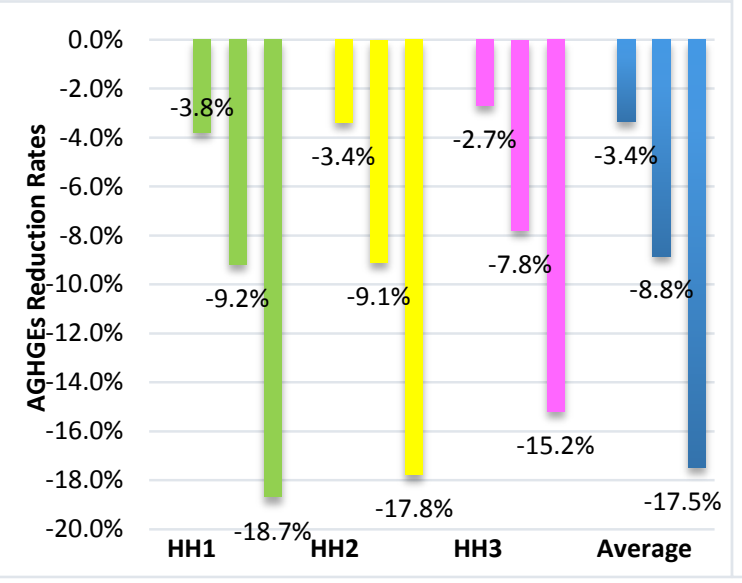

(A)

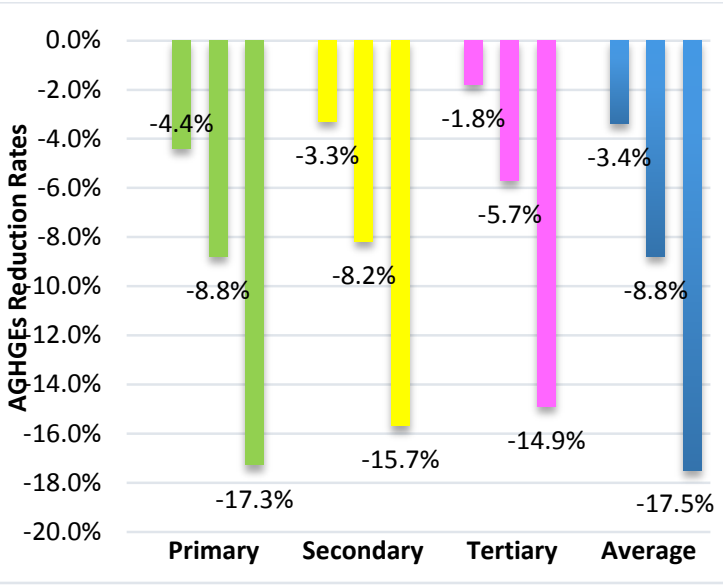

(B)

Fig. 7. Annual GHGEs reduction rates under fuel tax.

From Fig. 7 (A), we can observe that fuel tax reduces vehicle GHGEs for households with one, two, and three vehicles under all three policy plans. Different from purchase tax 
and ownership tax, fuel tax is more effective in reducing emissions for households with fewer vehicles. Besides, fuel tax has higher impact on emission reductions for vehicles used more frequently, as illustrated by Fig. 7 (B). The average households' annual GHGEs reduction rates under the three policy plans are $3.4 \%, 8.8 \%$, and $17.5 \%$.

\section{Conclusions}

The proposed model system is designed to forecast vehicle GHGEs and to evaluate effects of vehicle-related taxation schemes on private vehicle GHGEs. The model system integrates four sub-models: (a) vehicle type and vintage choice; (b) vehicle quantity choice; (c) vehicle usage choice; and (d) vehicle GHGEs rates estimator. The vehicle quantity model accounts for type/vintage preferences by incorporating the mode of the type/vintage sub-model. In order to estimate the annual VMT for each vehicle, the usage of households' primary, secondary, and tertiary vehicles are estimated by three linear regression models. The vehicle quantity probit model and the vehicle usage regression models are combined by an unrestricted full variance covariance matrix, which considers the interdependence between households' discrete and continuous choices. The model framework integrates with MOVES2014 which calculates emission rates for different vehicle types.

Using MOVES2014, we estimate the average GHGEs rates for the Washington D.C. Metropolitan Area. Both start/extended idle emission rates look-up tables and running emission rates look-up tables are developed.

The variables considered in our model system are vehicle characteristics, households' social demographics, land use variables, vehicle travel cost, and traffic condition information. The model is estimated with the 2009 NHTS data and supplementary datasets from the Consumer Report, the American Fact Finder, the 2009 SMVR, and MOVES default database.

The coefficients estimated by the integrated discrete-continuous car ownership model are significant, yielding a generally good correspondence to the observed situation. The vehicle GHGEs rates calculated by MOVES2014 and the vehicle GHGEs predicted by the integrated model system are consistent with EPA's annual report.

The impact of three vehicle-related taxation policies to reduce GHGEs are evaluated and compared. Three policy plans are proposed considering a series of equivalent increments of $\$ 92.5, \$ 185$, and $\$ 370$ annual fee per vehicle. The results indicate that: (a) Fuel tax is the most effective in reducing GHGEs compared to ownership tax and purchase tax under different tax rates; (b) Fuel tax has higher impact on emission reduction for households with fewer vehicles. This tax mainly reduces GHGEs by decreasing households' vehicle usage, especially for the low-income group; (c) Ownership taxes have the lowest impact on GHGEs reduction among the three different types of taxes. It reduces GHGEs by decreasing both households' vehicle quantity and usage; (d) Purchase taxes have higher impact for households with more vehicles. It mainly reduces GHGEs by decreasing households' vehicle quantity.

The conceptual framework developed is general and can be applied to other zones and counties. The model can be further expanded for application to state and national geographical level. Moreover, the inclusion of other variable types in the model makes it 
1 possible to test different taxation policies, and to support decisions aiming at reducing the

2 vehicle emission footprint.

3

\section{Acknowledgments}

5

This material is based upon work supported by the National Science Foundation

7 under Grant N. 1131535. Any opinions, findings, and conclusions or recommendations

8 expressed in this material are those of the authors and do not necessarily reflect the views 9 of the National Science Foundation.

10 


\section{Appendix A}

2

3 Sub-models input-output table.

\begin{tabular}{|c|c|c|c|}
\hline \multirow[t]{2}{*}{ SUB-MODELS } & \multicolumn{2}{|l|}{ INPUTS } & \multirow[t]{2}{*}{ OUTPUTS } \\
\hline & Variable Category & Parameters & \\
\hline $\begin{array}{l}\text { Vehicle Type and } \\
\text { vintage Sub-model }\end{array}$ & Vehicle characteristics & $\begin{array}{l}\text { Purchase price } \\
\text { Shoulder room } \\
\text { Luggage capacity } \\
\text { Average MPG } \\
\text { Vehicle make/model } \\
\text { Model year }\end{array}$ & $\begin{array}{l}\text { Estimated vehicle type } \\
\text { distribution } \\
\text { Logsum of vehicle } \\
\text { type }\end{array}$ \\
\hline $\begin{array}{l}\text { Vehicle Quantity } \\
\text { Sub-model }\end{array}$ & $\begin{array}{l}\text { HH socio-demographic } \\
\text { Land use }\end{array}$ & $\begin{array}{l}\text { Income } \\
\text { Number of drivers } \\
\text { HH head gender } \\
\text { Residential density } \\
\text { Vehicle type logsum }\end{array}$ & $\begin{array}{l}\text { Estimated } \mathrm{HH} \text { vehicle } \\
\text { quantity }\end{array}$ \\
\hline $\begin{array}{ll}\text { Vehicle } & \text { Usage } \\
\text { Sub-model } & \end{array}$ & $\begin{array}{l}\text { Vehicle VMT and cost } \\
\text { HH socio-demographic } \\
\text { Land use }\end{array}$ & $\begin{array}{l}\text { Income } \\
\text { HH head gender } \\
\text { Residential density } \\
\text { Fuel/Travel cost }\end{array}$ & $\begin{array}{l}\text { Estimated vehicle } \\
\text { AVMT }\end{array}$ \\
\hline $\begin{array}{l}\text { Vehicle Emission } \\
\text { Rate Sub-model }\end{array}$ & $\begin{array}{l}\text { Vehicle characteristics } \\
\text { Regional } \\
\text { conditions }\end{array}$ & $\begin{array}{l}\text { Vehicle type } \\
\text { Vehicle ownership } \\
\text { Vehicle VMT } \\
\text { Vehicle age } \\
\text { Vehicle speed } \\
\text { Vehicle population } \\
\text { Fuel type } \\
\text { Repair frequency } \\
\text { Local meteorology } \\
\text { Road type }\end{array}$ & $\begin{array}{l}\text { Vehicle emission rates } \\
\text { To calculate vehicle } \\
\text { annual GHGEs } \\
\text { To calculate HH } \\
\text { annual GHGEs }\end{array}$ \\
\hline
\end{tabular}




\section{References}

Bai, S., Eisinger, D., Niemeier, D., 2008. MOVES vs. EMFAC: A Comparison of Greenhouse Gas Emissions Using Los Angeles County. Submitted to TRB's 2009 Annual Meeting. Revised version: November 6, 2008.

Bhat, C. R., 2005. A multiple discrete-continuous extreme value model: formulation and application to discretionary time-use decisions. Transportation Research Part B, 2005, 39 (8), 679-707.

Bhat, C. R., Sen, S., 2006. Household vehicle type holdings and usage: an application of the multiple discrete-continuous extreme value (MDCEV) model. Transportation Research Part B, 2006, 40(1):35-53.

Bhat, C. R., Sen, S., Eluru, N., 2009. The impact of demographics, built environment attributes, vehicle characteristics, and gasoline prices on household vehicle holdings and use. Transportation Research Part B, 2009, 43(1):1-18.

Cirillo, C., Xu, R., Bastin, F., 2015. A dynamic formulation for car ownership modeling, Transportation Science, in press.

Dargay, J., Gamely, D., 1997. Vehicle ownership to 2015: implications for energy use and emissions. Energy Policy, Vol. 25, N. 14-15, pp. 1121-1127, 1997. PII:S03014215(97)00104- 3.

Davis, L. W., Kilian, L., 2009. Estimating the Effect of a Gasoline Tax on Carbon Emissions. Working paper, 2009.

Department of Ecology, State of Washington. Preparing for a Changing Climate, 2012. pp.3. http://www.ecy.wa.gov/climatechange/whatis.htm.

Dubin, J., McFadden, D., 1984. An econometric analysis of residential electric appliance holdings and consumption. Econometrica, 1984, 52(2):345-362.

Environmental Protection Agency, 1998. Technical Methods for Analyzing Pricing Measures to Reduce Transportation Emissions. EPA 231-R-98-006, August 1998.

USEPA, 2007. Motor Vehicle Emission Simulator Highway Vehicle Implementation (MOVES-HVI) Demonstration Version: Software Design and Reference Manual Draft. Publication EPA420-P-07-001, Office of Transportation and Air Quality, U.S. Environmental Protection Agency, 2007.

USEPA, 2011. Inventory of U.S. Greenhouse Gas Emissions and Sinks: 1990 - 2009. EPA 430-R-11-005, April, 2011. 
Environmental Protection Agency, 2013. Greenhouse Gas Emissions from a Typical Passenger Vehicle. Office of Transportation and Air Quality. EPA-420-F-13-033a, September 2013.

Eskeland, G. S., Devarajan, S., 1996. Taxing bads by taxing goods: pollution control with presumptive charges. The World Bank, Washington, D.C. Directions in development (Washington, D.C.), HJ5316.E578, 1996, 336.2-dc20.

Fang, H., 2008. A discrete-continuous model of households' vehicle choice and usage, with an application to the effects of residential density. Transportation Research Part B, 2008, 42 (9), 736-758.

Feng, Y., Fullerton, D., Gan, L., 2005. Vehicle Choices, Miles Driven and Pollution Policies. Working Paper 11553. http://www.nber.org/papers/w11553. 2005.

Fullerton, D., 2005. A Model to Evaluate Vehicle Emission Incentive Policies in Japan. Work papers available at: http://works.bepress.com/don_fullertion/10, January, 2005.

Fullerton, D., Gan, L., 2005. Cost-Effective Policies to Reduce Vehicle Emissions. The American Economic Review, Vol. 95, No. 2, Papers and Proceedings of the One Humdred Seventeenth Annual Meeting of the American Economic Association, Philidelphia, PA, January 7-9, 2005 (May). pp. 300-304.

Goulias, K. G., Bhat, C. R., Pendyala, R. M., Chen, Y., Paleti, R., Konduri, K. C., Lei, T., Yoon, S. Y., Huang, G., Hu., H. H., 2012. Simulator of Activities, Greenhouse Emissions, Networks, and Travel (SimAGENT) in Southern California. Presented at 91st Annual Meeting of the Transportation Research Board, Washington, D.C., 2012.

Hanemann, W. M., 1984. Discrete continuous models of consumer demand. Econometrica, 1984, 52(3):541-561. ISI Document Delivery No.: SV943 Times Cited: 168 Cited Reference Count: 28 Hanemann, WM Econometric Society Oxford.

Hayashi, Y., Kato, H., Teodoro, R. V. R., 2001. A model system for the assessment of the effects of car and fuel green taxes on $\mathrm{CO} 2$ emission. Transportation Research Part D: Transport and Environment, Washington, D.C., 2001, 6(2):123-139.

Jong, D., 1989. Simulating car cost changes using an indirect utility model of car ownership and car use; paper presented at PTRC SAM 1989, PTRC, Brighton, 1989b.

Liu, Y., 2013. Integrated Discrete-Continuous Choice Models: Theory and Applications in Estimating Household Vehicle Ownership, Type and Usage. Ph.D. Dissertation, University of Maryland, 2013. 
Liu, Y., Tremblay, J. M., Cirillo, C., 2014. An Integrated Model for Discrete and Continuous Decisions with Application to Vehicle Ownership, Type and Usage Choices. Transportation Research Board 93rd Annual Meeting, 14-2162, 2014.

Liu, Y., Cirillo, C., 2015. A Model System to Evaluate the Impacts of Vehicle Purchase Tax and Fuel Tax on Household Greenhouse Gas Emissions, Transportation Research Board 94th Annual Meeting, 2015, in press.

Mannering, F., Winston, C., 1985. A dynamic empirical analysis of household vehicle ownership and utilization. Rand Journal of Economics, 1985, 16-2, 215-236.

McCulloch, C. E., Searle, S. R., Neuhaus, J. M., 2008. Generalized, Linear, and Mixed Models. John Wiley \& Sons, Hoboken, New-Jersey, second edition, 2008.

Mcmichael, W. F., Sigsby, J. E., 1966. Automotive Emissions after Hot and Cold Starts in Summer and Winter. Journal of the Air Pollution Control Association, 16:9, 474477, DOI: 10.1080/00022470.1966.10468502.

Melnikov, O., 2013. Demand for Differentiated Durable Products: The Case of the U.S. Computer Printer Market. Economic Inquiry, 2013, vol. 51, issue 2, pages 12771298

Musti, S., Kockelman, K.M., 2011. Evolution of the household vehicle fleet: Anticipating fleet composition, PHEV adaptation and GHG emissions in Austin, Texas. Transportation Research Part A 45 (2011) 707-720.

Train, K., 1986. Qualitative choice analysis: theory, econometrics, and an application to automobile demand. MIT Press, Cambridge, Mass, 1986.

Vijayaraghavan, K., Lindhjem, C., DenBleyker, A., Nopmongcol, U., Grant, J., Tai, E., Yarwood, G., 2012. Effects of light duty gasoline vehicle emission standards in the United States on ozone and particulate matter. Atmospheric Environment 60 (2012) $109 \mathrm{e} 120$.

Vyas, G., Paleti, R., Bhat, C. R., Goulias, K. G., Pendyala, R. M., Hu, H. H., Adler, T. J., Bahreinian, A., 2012. Joint Vehicle Holding, by Type and Vintage, and Primary Driver Assignment Model with Application for California. Transportation Research Record: Journal of the Transportation Research Board. No. 2302, Transportation Research Board of the National Academics, Washington, D.C., 2012, pp. 74-83. DOI: $10.3141 / 2302-08$. 